\title{
Factors That Influence the Receipt of Well Baby Care in the First 2 Weeks of Life
}

\author{
Diane J. Madlon-Kay MD, MS, and Stephen E. Asche, MA
}

Purpose: To determine the percentage of babies born at a community hospital who received follow-up visits at home or clinic by 2 weeks of age. Also to describe the characteristics of the mothers whose newborns received visits within 2 weeks of birth.

Methods: A convenience sample of 335 mothers giving birth at a 430-bed community hospital in St. Paul, MN from September 2003 to September 2004 were surveyed by telephone when their infants were approximately 3- to 4-weeks old.

Results: $84 \%$ of the infants had a home or clinic visit within 2 weeks of birth. In bivariate analyses, the likelihood of having a visit within 2 weeks was significantly lower for mothers having more children $(P=.002)$, lower maternal education level $(P=.002)$, lower income $(P=.02)$, mothers' lack of knowledge of baby's insurance $(P=.02)$, mothers of nonwhite race $(P=.03)$, and mothers' having no medical insurance $(P=.04)$. The likelihood of a visit was not significantly related to whether English was spoken in the home or marital status. In logistic regression analyses, lower maternal education, and more children were significant predictors of the lack of visits.

Conclusions: Infants whose mothers had little education and had other children were a high-risk group that was less likely to receive care. When discharging newborns belonging to this group, extra effort should be made to ensure that appropriate postdischarge follow-up occurs. ( $\mathrm{J}$ Am Board Fam Med 2006;19:258-64.)

Traditionally newborns have been scheduled for their first well baby clinic visit at 2 weeks of age. ${ }^{1}$ An additional follow-up visit at home or clinic within 2 days of discharge has been recommended by the American Academy of Pediatrics (AAP) since 1995 for newborns discharged less than 48 hours after delivery. ${ }^{2}$ A visit at this time allows an infant to be observed by a clinician at 3 to 5 days of life, which is the usual peak of serum bilirubin concentration. In addition, breastfeeding mothers discharged early do not have time for their lactation to become well-established. Therefore this visit also enables the clinician to assess the adequacy of breastfeeding. Studies indicate that providers have not consistently followed the AAP guidelines for early follow-up. ${ }^{1,3}$

Submitted 24 September 2005; revised 30 November 2005; accepted 2 December 2005.

From Smiley's Family Medicine Residency Program, University of Minnesota, St. Paul, MN (DJM-K); and HealthPartners Research Foundation, Bloomington, MN (SEA)

Funding: This study was funded by the HealthPartners Research Foundation.

Conflict of interest: none declared.

Corresponding author: Diane J. Madlon-Kay MD, Smiley's Clinic, 2615 East Franklin Ave., Minneapolis, MN 55406 (E-mail: madlo001@tc.umn.edu).
Previous studies have identified many barriers to well child care. Mothers in a rural state identified barriers to well child care as falling into the following categories: financial, inconvenience, unavailability of providers, lack of knowledge of well-child schedule, and other (including the belief that preventive care is not necessary). ${ }^{4}$ In contrast, Hispanic parents cite language problems as the greatest barrier to health care for their children. ${ }^{5}$ Hispanic and black children seemed to have more barriers to care than white children in a report of multiple disparities in early childhood health status, insurance coverage, parental satisfaction, referrals to specialists, and other measures of health care. ${ }^{6}$

The purpose of this study was to use telephone surveys to mothers approximately 3 weeks after giving birth at Regions Hospital in St. Paul, MN for the following aims:

1. To determine the percentage of newborns receiving home or clinic visits within 2 weeks of birth.

2. To describe the characteristics of mothers of newborns who do not receive home or clinic visits within 2 weeks of birth. 
Approximately $20 \%$ of the women who deliver at Regions Hospital are Hispanic and 10\% are Hmong (the Hmong are an ethnic group originally living in southern China, Vietnam, Laos, and Thailand). Many of the women from these ethnic groups want to be discharged as soon as possible, typically at 24 hours postpartum. We hypothesized that many women are not getting the early follow-up visit that is recommended by the AAP nor the traditional 2 week visit. We also hypothesized that the newborns whose mothers' primary language is English are more likely to receive home or clinic visits within 2 weeks of birth. Other variables studied included whether the newborn has medical insurance, the number of other children, and maternal education level. The study was initiated by and study objectives determined by one of the authors (DJM) who frequently worked in the Regions Hospital newborn nursery.

\section{Methods}

The study took place at Regions Hospital, a 430bed hospital in St. Paul, MN. There are approximately 2200 deliveries yearly, done by obstetricians, family physicians, and midwives. Family physicians and pediatricians provide care for the babies in the nursery and make recommendations for the follow-up visits. The clinic visits take place in doctors' offices or community health centers. Home health nurse visits are provided by home health nurse agencies or public health nurses. The HealthPartners Institutional Review Board approved the study.

While in the hospital after delivery, women were given a letter to read about the study, including the option to decline to participate. The letter was also translated into Spanish and Hmong and given to women who primarily speak those languages. At the time of discharge, a postpartum nurse determined whether a woman was eligible for the study and, if so, obtained contact information. The nurse also indicated what type of insurance the woman had, if any. A woman was excluded from the study for the following reasons: if she and her baby were not discharged the same day; if this delivery was twins or a multiple birth; if she did not speak English, Spanish, or Hmong; if she did not have a telephone; or if her age was less than 18 years. The first 2 exclusions were to attempt to decrease the number of sick newborns that were included in the study. The last exclusion was because review board approval was for adults only.

The HealthPartners Survey center began trying to contact and survey eligible women by telephone approximately 3 to 4 weeks after delivery. The survey questions were based on questions used in a series of studies of models of postpartum care at Kaiser Permanente. ${ }^{7-9}$ The survey was piloted on 28 English-speaking mothers. The interviews were done in the English, Spanish, and Hmong languages. If English was not the primary language of an English-speaking mother, the nurse only enrolled a mother fluent enough to successfully complete a telephone survey.

Study recruitment occurred from September 2003 to September 2004. Initially an OB case manager who saw all the women at discharge recruited women for the study when she worked. When her position was eliminated, the regular postpartum nurses did the recruitment as their time allowed.

\section{Sample}

A total of 355 woman participated in the study. After 228 English-speaking women had been enrolled, only Spanish- and Hmong-speaking women were enrolled for the remainder of the study. We initially aimed to enroll a total of 333 women in the study: 233 English speaking and 100 non-English speaking. With this sample size we would have an $80 \%$ power to detect a $13 \%$ difference between the English and non-English groups in the percentage of newborns receiving home or clinic visits within 2 weeks of birth.

\section{Measures}

After explaining the study to the mother, the postpartum nurse recorded the delivery and discharge dates and times, the age of the baby at which a home or clinic follow-up was recommended, and the mother's insurance (Medicaid, other insurance, none). The clinic follow-up appointment was made by the mother herself, not the nurse. A follow-up phone survey was initiated approximately 3 weeks after infant delivery (the median time from delivery to survey completion was 26 days). This 5 -minute survey contained 20 items concerning frequency of infant checkups, when and where checkups occurred, attitudes toward checkups, sociodemographic background, and living situation. The survey center made up to 20 attempts to reach mothers by phone. 


\section{Analysis}

Analysis began by examining frequency distributions on all items. Bivariate associations between the main study variable (one or more home or clinic visits within the first 14 days of age) and other items were examined with contingency tables and tested using Pearson's $\chi^{2}$ for non-ordered items and the Mantel-Haenszel test for trend for items having ordinal categories.

Logistic regression was used to test the adjusted effect of language spoken in the home on the likelihood of a home or clinic visit within 2 weeks. Covariates in this analysis were selected a prioribased on our interest in testing hypotheses about specific possible explanatory variables. Covariates included length of stay, maternal education, number of children, and baby's insurance status. A reduced model was then fit to more parsimoniously describe the association between home or clinic visits and explanatory variables. Items having borderline significance $(P<.20)$ in the full model were retained for the reduced model. Other items were dropped as a group, and a likelihood ratio test comparing the full and reduced model was conducted to test the effect of removing this set of items. Statistical analyses were performed using SAS statistical software version 8 . All tests of hypotheses were 2 -sided and values of $P<.05$ were considered statistically significant.

\section{Results}

A total of 542 women were assessed for their eligibility for the study; 88 women were not eligible for the following reasons: twins, 2; age less than 18 years, 14; no telephone, 7; mother discharged without the baby, 34; not sufficiently fluent in English for English interview, 31. The survey center was unable to reach 72 women because of incorrect telephone numbers or no answers despite multiple attempts. Twenty women declined to be interviewed when called by the survey center. Seven completed surveys were eliminated because they took place when the infant was $<18$ days or $>100$ days old. The remaining sample size is 355 women.

Table 1 describes the characteristics of the women based on responses from the phone survey as well as insurance status as recorded by the postpartum nurse.

Mother/infant length of stay ranged from 24 to 194 hours; $57 \%$ were discharged before 48 hours.
According to the documentation made by the discharge nurse, the first home or clinic follow-up visit was recommended at 1 week of age or younger for $30 \%$ of infants, and between 8 to 17 days for the remaining $70 \%$ of infants. Nearly all (97\%) mothers reported being told at discharge when the baby should be seen in clinic for the first checkup. In $56 \%$ of cases, mothers' reports agreed exactly with the discharge form regarding the timing of the first clinic visit. Eight mothers reported being told the first visit should be when the baby is older than 2 weeks, including one as late as 44 days.

By the time of the survey, $41 \%$ of the mothers and infants had one or more home health nurse visits, and $93 \%$ of the mothers had taken their infants to the clinic for a checkup or examination. More than one-third (37\%) of the infants had home visits within the first 2 weeks of life and 74\% of newborns had clinic visits within the first 2 weeks of life. Overall, $84 \%$ of newborns had a home or clinic visit in the first 2 weeks of life.

The recommendations for when the first visit should occur did not differ by whether the infant was discharged before or after 48 hours of age. Infants discharged in fewer than 48 hours had a follow-up visit recommended at a mean of 11.1 days, whereas those discharged at 48 hours or more had a follow-up visit recommended at a mean of 11.6 days $(P=.36)$.

Most mothers traveled to the baby's first clinic visit via their own cars (66\%) or someone else's car (29\%). Most mothers reported that the doctor or nurse doing the baby's first checkup spoke the mother's language or used an interpreter (80\%). A total of $95 \%$ of mothers agreed that well baby checkups are very important and 5\% said that they are somewhat important. None thought that the checkups were unimportant.

Table 2 demonstrates the association of a number of maternal factors and the receipt of home or clinic visits in the first 2 weeks of the newborn's life. Language spoken in the home was not significantly associated with a home or clinic office visit by 2 weeks of age $(P=.08)$. Having fewer children, higher education, and higher household income were associated with a higher likelihood of having a home or clinic visit within 2 weeks. Visits within 2 weeks were also significantly associated with the mother's having health insurance $(P=.04)$ and the mothers' report of the infants' insurance status $(P=.02)$. Race/ethnicity is not significant in Table 


\begin{tabular}{|c|c|c|}
\hline Characteristic & Number $(\mathrm{n}=355)$ & Percentage \\
\hline \multicolumn{3}{|l|}{ Race or ethnicity } \\
\hline White & 89 & 25.4 \\
\hline Hispanic & 139 & 39.6 \\
\hline Black & 51 & 14.5 \\
\hline American Indian & 4 & 1.1 \\
\hline Asian & 63 & 18.0 \\
\hline Multicultural & 5 & 1.4 \\
\hline (Missing) & 4 & \\
\hline \multicolumn{3}{|l|}{ Marital status } \\
\hline Married & 198 & 56.1 \\
\hline Living with boyfriend or partner & 97 & 27.5 \\
\hline Divorced, widowed, or separated & 9 & 2.6 \\
\hline Never married & 49 & 13.9 \\
\hline (Missing) & 2 & \\
\hline \multicolumn{3}{|c|}{ Number of children other than newborn } \\
\hline 0 & 137 & 38.8 \\
\hline 1 & 117 & 33.1 \\
\hline 2 & 55 & 15.6 \\
\hline 3 & 28 & 7.9 \\
\hline 4 & 7 & 2.0 \\
\hline 5 & 6 & 1.7 \\
\hline $6+$ & 3 & 0.8 \\
\hline (Missing) & 2 & \\
\hline \multicolumn{3}{|l|}{ Highest education } \\
\hline Less than high school & 119 & 34.2 \\
\hline High school graduate & 95 & 27.3 \\
\hline Some college or technical school & 62 & 17.8 \\
\hline College graduate & 72 & 20.7 \\
\hline (Missing) & 7 & \\
\hline \multicolumn{3}{|l|}{ Annual household income } \\
\hline$\leq \$ 20,000$ & 179 & 62.8 \\
\hline$\$ 20,001-\$ 40,000$ & 47 & 16.5 \\
\hline$\$ 40,001-\$ 60,000$ & 24 & 8.4 \\
\hline$>\$ 60,000$ & 35 & 12.3 \\
\hline (Missing) & 70 & \\
\hline \multicolumn{3}{|l|}{ Language spoken in home } \\
\hline English & 184 & 51.8 \\
\hline Spanish & 112 & 31.6 \\
\hline Hmong & 38 & 10.7 \\
\hline Other & 21 & 5.9 \\
\hline \multicolumn{3}{|l|}{ Mother's insurance: } \\
\hline Medicaid & 182 & 51.3 \\
\hline Other insurance & 164 & 46.2 \\
\hline None & 9 & 2.5 \\
\hline \multicolumn{3}{|l|}{ Length of stay } \\
\hline 24 to 47 hours & 203 & 57.2 \\
\hline 48 to 95 hours & 139 & 39.2 \\
\hline$\geq 96$ hours & 13 & 3.7 \\
\hline \multicolumn{3}{|l|}{ Does new baby have medical insurance? } \\
\hline Yes & 248 & 70.5 \\
\hline No & 87 & 24.7 \\
\hline Don't know & 17 & 4.8 \\
\hline (Missing) & 3 & \\
\hline
\end{tabular}




\begin{tabular}{|c|c|c|c|}
\hline Characteristic & $\mathrm{N}$ & Percentage & $P$ Value \\
\hline \multicolumn{4}{|l|}{ Language spoken in home } \\
\hline English & 139 & 87.4 & \multirow[t]{2}{*}{$.08^{*}$} \\
\hline All other languages & 158 & 80.6 & \\
\hline \multicolumn{4}{|l|}{ Number of other children } \\
\hline 0 & 121 & 88.3 & \multirow[t]{4}{*}{$.002 \dagger$} \\
\hline 1 & 99 & 84.6 & \\
\hline 2 & 46 & 83.6 & \\
\hline 3 or more & 29 & 65.9 & \\
\hline \multicolumn{4}{|l|}{ Highest education level } \\
\hline Less than high school & 94 & 79.0 & \multirow[t]{4}{*}{$.002 \dagger$} \\
\hline High school graduate & 74 & 77.9 & \\
\hline Some college or technical school & 55 & 88.7 & \\
\hline College graduate & 68 & 94.4 & \\
\hline \multicolumn{4}{|l|}{ Annual household income } \\
\hline$\leq \$ 20,000$ & 144 & 80.5 & \multirow[t]{4}{*}{$.02 \dagger$} \\
\hline$\$ 20,001-\$ 40,000$ & 39 & 83.0 & \\
\hline$\$ 40,001-\$ 60,000$ & 22 & 91.7 & \\
\hline$>\$ 60,000$ & 33 & 94.3 & \\
\hline \multicolumn{4}{|l|}{ Maternal medical insurance } \\
\hline Medicaid & 150 & 82.4 & \multirow[t]{3}{*}{$.04^{*}$} \\
\hline Other insurance & 142 & 86.6 & \\
\hline None & 5 & 55.6 & \\
\hline \multicolumn{4}{|l|}{$\begin{array}{l}\text { Does new baby have medical } \\
\text { insurance? }\end{array}$} \\
\hline Yes & 215 & 86.7 & \multirow[t]{3}{*}{$0.02^{*}$} \\
\hline No & 69 & 79.3 & \\
\hline Don't know & 11 & 64.7 & \\
\hline \multicolumn{4}{|l|}{ Race or ethnicity } \\
\hline White & 81 & 91.0 & \multirow[t]{5}{*}{$0.10^{*}$} \\
\hline Hispanic & 117 & 84.2 & \\
\hline Black & 41 & 80.4 & \\
\hline Other & 7 & 77.8 & \\
\hline Asian & 47 & 74.6 & \\
\hline \multicolumn{4}{|l|}{ Marital Status } \\
\hline Married & 165 & 83.3 & \multirow[t]{4}{*}{$0.19^{*}$} \\
\hline Living with boyfriend or partner & 84 & 86.6 & \\
\hline Divorced, widowed, separated & 9 & 100 & \\
\hline Never married & 37 & 75.5 & \\
\hline
\end{tabular}

* Based on Pearson $\chi^{2}$.

† Based on Mantel-Haenszel test for trend.

2, unless it is re-categorized as white $(91.0 \%$ have 2 week visit) versus nonwhite $(80.9 \%$ have 2 week visit), $\chi^{2}(1)=4.91, P=.03$.

A logistic regression analysis was estimated predicting one or more home or clinic visits within 2 weeks of infant delivery from language spoken in the home, maternal education, number of children, baby's insurance status, and length of stay-and yielded a nonsignificant adjusted odds ratio for lan- guage spoken in the home: OR ("other languages" vs. English) $=1.35,95 \%$ CI: $0.66-2.77, P=.41$. Higher maternal education was the only item significantly associated with home or clinic visits $(P=$ $.03)$ in this model, whereas a lower number of children was marginally associated with visits $(P=$ .08). A second reduced model predicting home or clinic visits from only maternal education and number of children is shown in Table 3. A likelihood 
Table 3. Logistic Regression Model Predicting One or More Home or Clinic Visits within 2 Weeks of Infant Delivery

\begin{tabular}{lccc}
\hline & OR & $95 \%$ CI & $P$ Value \\
\hline $\begin{array}{l}\text { Maternal education } \\
\text { Some college or more }\end{array}$ & 2.84 & $1.32-6.11$ & .007 \\
High school & 0.85 & $0.44-1.67$ & .64 \\
$\quad$ Less than high school & REF & & \\
$\begin{array}{l}\text { Number of children other } \\
\text { than new infant }\end{array}$ & & & \\
$\geq 2$ & 0.42 & $0.21-0.86$ & 0.02 \\
$1 \quad 0.73$ & $0.35-1.53$ & 0.41 \\
None & REF & & \\
\hline
\end{tabular}

ratio test comparing the full and reduced models indicates little predictive ability is lost by selecting the reduced model $\left(\chi^{2}(3)=2.17, P=.54\right)$. In the reduced model, mothers who were college educated (vs. less than high school) were more likely to have infants with a home or clinic visit within 2 weeks, whereas mothers having 2 or more other children (vs. no other children) were less likely.

\section{Discussion}

Approximately 1 in 6 newborns in this study did not have health care professional visits by 2 weeks of age. According to the multivariate analysis, the women most at risk for failing to have a follow-up visit for their infants were those with 2 or more additional children and those without a high school education.

The physicians were clearly not following AAP guidelines for early follow-up of infants discharged before 48 hours of age. One potential barrier to appropriate follow-up is a physician lack of concern about jaundice. ${ }^{10}$ Most pediatricians and family physicians have never seen a case of kernicterus and therefore may have a cavalier attitude toward jaundice. Insurance policies may also present a barrier to appropriate follow-up by not providing routine coverage for systematic follow-up by a clinician. ${ }^{10}$ Physician education has been shown to improve newborn discharge orders consistent with AAP policy. ${ }^{1,11}$ The latest AAP guidelines recommend early follow-up for infants discharged before 72 hours of age, which is $89 \%$ of the study population. ${ }^{12}$ The AAP is working on an implementation program to increase the level of physician compliance with the new guidelines. ${ }^{10}$
Mothers in this study had to make their own appointments for their babies' first clinic appointments. They were not required to make the appointment before discharge. However, making the babies' first appointment before discharge has been shown in one study to increase significantly the timeliness for the first newborn appointment. ${ }^{13}$

It is surprising that language did not prove to be significantly associated with lack of follow-up visits, since such disparities have been noted in several other studies. ${ }^{5,14,15}$ It was encouraging that $80 \%$ of mothers whose primary language is not English reported that the doctor or nurse who did the baby's first checkup spoke her language or used an interpreter. However, it also means that for $20 \%$ of the mothers, communication was suboptimal for this important visit.

Two previous studies have reported on patient follow-up with the first newborn visit after hospital discharge. ${ }^{15,16}$ In the study by Feinberg and colleagues, late was defined as appearance for an appointment greater than 24 hours after the time stated on the hospital discharge $\operatorname{order}^{16}$ (weekends and holidays were not counted). Medicaid patients were late significantly more often, as were younger mothers. There was no difference in frequency of lateness with the distance from the patients' home to the medical facility.

In a population-based survey of mothers giving birth in California, untimely follow-up was defined as no home or office visit within 2 days of early discharge. ${ }^{15}$ Untimely follow-up was more likely for infants of women with incomes $\leq 100 \%$ of poverty and $201 \%$ to $300 \%$ of poverty, Medicaid coverage, Latina ethnicity, and non-English language.

The study has several limitations. The study participants were a convenience sample. Therefore these results may not be generalizable to other mothers and newborns. It is possible that because the mothers knew they would be called and asked about well baby care, they might have changed their behavior regarding the visits (the Hawthorne effect). Because women without telephones were excluded, study results are limited to women with telephones. Fortunately only $1.3 \%$ of the women screened for eligibility in this study did not have telephones.

In summary, many newborns are not receiving the recommended postdischarge follow-up, including the 2 week visit. Newborns are at increased risk of not receiving care if their mothers are less edu- 
cated and have other children. When discharging newborns belonging to this high-risk group, physicians should make an extra effort to ensure appropriate follow-up, such as making the clinic appointment before discharge.

\section{References}

1. Maisels MJ, Kring E. Early discharge from the newborn nursery - effect on scheduling of follow-up visits by pediatricians. Pediatrics 1997;100:72-4.

2. Committee on Fetus and Newborn. Hospital stay for healthy term newborns. Pediatrics 1995;96:788-90.

3. Madlon-Kay DJ. Evaluation and management of newborn jaundice by midwest family physicians. J Fam Pract 1998;47:461-4.

4. Earle L, Burman M. Benefits and barriers to wellchild care: perceptions of mothers in a rural state. Public Health Nurs 1998;15:180-7.

5. Flores G, Abreu M, Olivar MA, Kastner B. Access barriers to health care for Latino children. Arch Pediatr Adolesc Med 1998;152:1119-25.

6. Flores G, Olson L, Tomany-Korman SC. Racial and ethnic disparities in early childhood health and health care. Pediatrics 2005;115:e183-93.

7. Lieu TA, Braveman PA, Escobar GJ, Fischer AF, Jensvold NG, Capra AM. A randomized comparison of home and clinic follow-up visits after early postpartum hospital discharge. Pediatrics 2000;15:105865.

8. Lieu TA, Wikler C, Capra AM, Martin KE, Escobar
GJ, Braveman PA. Clinical outcomes and maternal perceptions of an updated model of perinatal care. Pediatrics 1998;102:1437-44.

9. Escobar GJ, Braveman PA, Ackerson L, et al. A randomized comparison of home visits and hospitalbased group follow-up visits after early postpartum discharge. Pediatrics 2001;108:719-27.

10. Lannon C, Stark AR. Closing the gap between guidelines and practice: ensuring safe and healthy beginnings. Pediatrics 2004;114:494-6.

11. Feinberg AN, Hicks WB. Quality improvement and patient compliance with appointments. Clin Pediatr 2002;41:515-7.

12. Subcommittee on Hyperbilirubinemia. Management of hyperbilirubinemia in the newborn infant 35 or more weeks of gestation. Pediatrics 2004;114:297316.

13. Feinberg AN, McAllister DG, Majumdar S. Does making newborn follow-up appointments from the hospital improve compliance? J Perinatol 2004;24: 645-9.

14. Woloshin S, Bickell NA, Schwartz LM, Gany F, Welch HG. Language barriers in medicine in the United States. JAMA 1995;273:724-8.

15. Galbraith AA, Egerter SA, Marchi KS, Chavez G, Braveman PA. Newborn early discharge revisited: are California newborns receiving recommended postnatal services? Pediatrics 2003;111:364-71.

16. Feinberg AN, Hicks WB. Patient compliance with the first newborn visit appointment. J Perinatol 2003;23:37-40. 